\title{
Changes in the Physicochemical Characteristics of Peanut Straw Biochar after Freeze-Thaw and Dry-Wet Aging Treatments of the Biomass
}

\author{
Yongqiang Cao, ${ }^{\mathrm{a}, \mathrm{b}}$ Yande Jing,,${ }^{\mathrm{a}, \mathrm{b}, *}$ Hao Hao, ${ }^{\mathrm{a}, \mathrm{b}}$ and Xuan Wang ${ }^{\text {a,b }}$ \\ Effects of aging after pyrolysis were tested relative to the physicochemical \\ characteristics of peanut straw biochar. Biochar was prepared at pyrolysis \\ temperatures of $350^{\circ} \mathrm{C}, 500^{\circ} \mathrm{C}$, and $650{ }^{\circ} \mathrm{C}$; then, it was freeze-thawed \\ and dry-wet aged. The physicochemical characteristics of the fresh and \\ aged biochar were analyzed. The results showed that the pyrolysis \\ temperature, ambient temperature, and humidity affected the \\ physicochemical characteristics of the biochar. With the increase of \\ pyrolysis temperature, the yield and surface acidic functional groups of the \\ fresh biochar decreased, whereas the ash content, $\mathrm{C}$ content, $\mathrm{pH}$, specific \\ surface area, and mesoporous volume of the fresh biochar increased. The \\ aging treatment increased the acidic functional groups content in the \\ biochar and reduced the aromatic functional groups content, which \\ decreased the $\mathrm{pH}$ value of the biochar. The aging treatment increased the \\ specific surface area and pore volume of the biochar, and the effect of \\ freeze-thaw aging was greater than that of dry-wet aging. The aging \\ treatment also destroyed the complete shape of the fresh biochar, and \\ reduced its stability. After the aging treatment, the $\mathrm{C}$ content of the biochar \\ decreased, whereas the $O$ content increased, due to oxidation of the \\ biochar.
}

Keywords: Biochar; Aging; Dry-wet; Freeze-thaw; Peanut straw

Contact information: a: College of Geography and Tourism, Qufu Normal University, 80 Yantai Road, Rizhao, Shandong, 276826, China; b: Key Laboratory of Nansi Lake Wetland Ecological and

Environmental Protection in Universities of Shandong, 57 Jingxuan Road, Jining, Shandong, 273165, China; *Corresponding author: jingyande@163.com

\section{INTRODUCTION}

Abandoned crops are often burned without limitations. This can lead to ecological damage and environmental pollution in rural ecology, and there are high losses of biomass resources (Chen et al. 2011). Biochar is a stable form of carbon that can be produced from the pyrolysis process of waste straw under limited oxygen conditions and relatively lowtemperature conditions of incineration $\left(<700{ }^{\circ} \mathrm{C}\right)$ (Joseph et al. 2010). This material has gained great attention for agricultural applications (Iftikhar et al. 2018), environmental protection (O'Connor et al. 2018), and energy (Dong et al. 2018), as well as other areas in recent years. Biochar is a hard-to-degrade material in its natural state (Leng and Huang 2018), and has been produced from terra preta for hundreds or even thousands of years (Glaser et al. 2002). However, the physicochemical characteristics of biochar are not constant and experience slow physicochemical changes during exposure to soil (Zhang et al. 2012). Because biochar in the soil experiences a changing environment (changing temperature, humidity, etc.), its physicochemical properties change over time in a process called biochar aging. This process includes biotic and abiotic redox reactions in the soil; 
interactions of organic matter, minerals, and solute; effects due to microorganisms; and various other factors.

Seasonal changes, wind and rain erosion (Hao et al. 2017), and freeze-thaw cycles (Xu et al. 2018) all change the physical structure of biochar in soil. Studies have examined the effects of aging processes of the biochar by physical (Zhang et al. 2015b; Ren et al. 2018), chemical (Fan et al. 2018), and biological methods (Hale et al. 2011). It was found that the physicochemical characteristics of biochar, such as the surface morphology, cation exchange capacity, $\mathrm{pH}$, elemental composition, and ash content, could be changed by aging processes (Heitkötter and Marschner 2015). Such changes in the physicochemical characteristics can influence the effects of biochar on soil improvement, environmental remediation, climate improvement, etc. Presently, many studies mainly focus on the single freeze-thaw or dry-wet aging effects on biochar, and there have been few comparative studies on freeze-thaw and dry-wet aging effects on biochar.

To achieve an improved understanding of the effects of biochar aging on its properties, peanut straw biochar was prepared in this study at different pyrolysis temperatures, and the aging process of biochar was accelerated by freeze-thaw and dry-wet cycles. The main objective of this study was to identify the changes in the physicochemical characteristics of peanut straw biochar before and after the aging processes. The results of this study could provide a theoretical basis for the aging of biochar in the soil environment and the effective utilization of biochar.

\section{EXPERIMENTAL}

\section{Soil and Straw Sources}

Soil $(10 \mathrm{~cm}$ to $20 \mathrm{~cm})$ was collected from Rizhao, China $\left(35^{\circ} 30^{\prime} \mathrm{N}, 119^{\circ} 16^{\prime} \mathrm{E}\right)$. The soil was passed through a $0.150-\mathrm{mm}$ sieve before being used for the aging experiments. The type of soil was burozem and classified as Cambisol according to the World Reference Base for Soil Resources (Surhone et al. 2002). Its pH was 6.06, its water-holding capacity was $23.05 \%$, and the organic content was $10.9 \mathrm{~g} / \mathrm{kg}$ (Table 1). The straw was peanut straw, which was collected from Rizhao, China in 2015. After air-drying and milling, the peanut straw was used to prepare the biochar.

Table 1. Basic Physicochemical Properties of Soil

\begin{tabular}{|c|c|c|c|c|c|c|c|}
\hline \multirow{2}{*}{ Soil type } & $\mathrm{pH}$ & $\begin{array}{c}\text { Water-holding } \\
\text { capacity } \\
\end{array}$ & $\begin{array}{c}\text { Organic } \\
\text { content } \\
(\%)\end{array}$ & \multirow{2}{*}{$\begin{array}{c}\text { CEC } \\
\left(\mathrm{g} \mathrm{kg}^{-1}\right)\end{array}$} & \multicolumn{3}{|c|}{ Mechanical composition (\%) } \\
\cline { 5 - 8 } & & & $\begin{array}{c}0.02 \text { to } 2 \\
\mathrm{~mm}\end{array}$ & $\begin{array}{c}0.002 \text { to } \\
0.02 \mathrm{~mm}\end{array}$ & $\begin{array}{c}<0.002 \\
\mathrm{~mm}\end{array}$ \\
\hline Burozem & 6.06 & 23.5 & 10.9 & 20.04 & 46.0 & 25.0 & 29.0 \\
& \pm 0.03 & \pm 3.10 & \pm 2.40 & \pm 3.71 & \pm 2.00 & \pm 3.00 & \pm 2.00 \\
\hline
\end{tabular}

\section{Biochar Preparation}

The peanut straw (Rizhao, China) was used as the raw material to prepare biochar by pyrolyzation at $350{ }^{\circ} \mathrm{C}, 500{ }^{\circ} \mathrm{C}$, and $650{ }^{\circ} \mathrm{C}$. Fresh peanut straw was air-dried and ground, placed in crucibles, and put into a muffle furnace (KSY-12D-16, Longkou City Factory Furnace, Wuhan, China). The peanut straw biochar was pyrolyzed in oxygenlimited, low-temperature conditions (Wang et al. 2015), with the inert atmosphere achieved with an $\mathrm{N}_{2}$ flowrate of $0.5 \mathrm{~L} / \mathrm{min}$. The three temperatures were reached at a rate of 20 
${ }^{\circ} \mathrm{C} / \mathrm{min}$ and maintained for $30 \mathrm{~min}$. Then, the fresh biochar was cooled to $25{ }^{\circ} \mathrm{C}$, passed through a $0.150-\mathrm{mm}$ sieve, and analyzed. The peanut straw biochar was marked as P-350, $\mathrm{P}-500$, and P-650, with the numbers indicating the pyrolysis temperature in ${ }^{\circ} \mathrm{C}$.

\section{Aging Experiments}

The freeze-thaw aging experiment was performed in PVC plastic containers (diameter $=5 \mathrm{~cm}$, and height $=30 \mathrm{~cm}$ ), which were filled with fresh biochar on the top of the soil. Approximately $100 \mathrm{~g}$ of soil (from Rizhao, China, passed through a $0.850-\mathrm{mm}$ sieve) were placed into the plastic containers under the biochar. The biochar and soil were separated by a nylon net with a mesh size of $0.075 \mathrm{~mm}$. Before freeze-thaw aging, the biochar was leached with approximately $100 \mathrm{~mL}$ of deionized water. Then, the PVC plastic containers were placed in a constant temperature and humidity chamber (GDWJS-250, Shanghai Baidian Instrument Equipment Co., Ltd., Shanghai, China), held at $-15^{\circ} \mathrm{C}$ for 30 $\mathrm{d}$, and then held at $45^{\circ} \mathrm{C}$ for $30 \mathrm{~d}$. After freeze-thaw aging, the biochar samples were dried at $60{ }^{\circ} \mathrm{C}$, passed through a $0.150-\mathrm{mm}$ sieve (Miao 2014), and marked as PF-350, PF-500, and PF-650.

The dry-wet aging experiment was implemented in plastic containers $(30 \mathrm{~cm} \times 15$ $\mathrm{cm} \times 20 \mathrm{~cm}$ ) filled with fresh biochar and soil. The biochar and soil were separated by a nylon net with a mesh size of $0.075 \mathrm{~mm}$. The plastic containers filled with fresh biochar and soil were placed in an artificial climate chamber (ZRQ-400, Shanghai Gemtop Scientific Instrument Co., Ltd., Shanghai, China). The dry-wet aging experiment was performed at $25^{\circ} \mathrm{C}$ and a humidity of $30 \%$ for $20 \mathrm{~d}$, followed by $20 \mathrm{~d}$ at a humidity of $90 \%$ (Guo et al. 2014; Miao 2014). After dry-wet aging, the aged biochar samples were marked as PD-350, PD-500, and PD-650.

\section{Analysis of the Biochar Characteristics}

The biochar and peanut straw were weighed with an electronic scale (AUX220, Shimadzu, Kyoto, Japan), and then the biochar yield was calculated (GB/T 17664 1999). The ash contents were determined based on GB/T 12496.3 (1999). The $\mathrm{pH}$ was measured according to GB/T 12496.7 (1999). Biochar samples were mixed with deionized water at a ratio of 1:20 (w/v) and stirred with an electromagnetic stirrer for $5 \mathrm{~min}$. After standing for $30 \mathrm{~min}$, the $\mathrm{pH}$ of the mixture was measured using a digital $\mathrm{pH}$ meter (PHS-3C, Shanghai INESA Scientific Instrument CO., LTD, Shanghai, China).

The $\mathrm{C}, \mathrm{H}$, and $\mathrm{N}$ concentrations were determined with an elemental analyzer (EA3000, EuroVector, Milan, Italy). The total C, H, and $\mathrm{N}$ were determined on the basis of the dry weight in an oxygen-enriched atmosphere. The $\mathrm{O}$ concentration was calculated by subtraction $(\mathrm{O} \%=100 \%-(\mathrm{C} \%+\mathrm{H} \%+\mathrm{N} \%+\mathrm{ash} \%)$ (Zhang et al. 2015a; Hao et al. 2017).

The Brunauer-Emmett-Teller (BET) surface areas of the biochar samples were measured by the nitrogen gas adsorption-desorption method (V-Sorb 2800P, Beijing Jinepu Technology Co., Ltd., Beijing, China) using a specific surface area and pore size analyzer. The surface areas were measured from a multi-point plot of relative pressure $\left(P / P_{0}\right)$ over the range of 0.05 to 0.35 (Ju et al. 2017).

Fourier-transform infrared (FTIR) spectroscopy was performed using an FTIR spectrometer (Tensor 27, Bruker, Karlsruhe, Germany) to characterize the surface functional groups of the biochar. 
The biochar samples were ground and mixed with $\mathrm{KBr}$, and were then pressed into pellets. At a $4 \mathrm{~cm}^{-1}$ resolution, the spectra were obtained over the range of $500 \mathrm{~cm}^{-1}$ to 4000 $\mathrm{cm}^{-1}$ with 64 scans. The software Origin 9.1 (OriginLab, Northampton, MA, USA) was used for data analysis and drawing (Hao et al. 2017).

Scanning electron microscopy (SEM) images of the biochar were obtained using a JSM-6700F (JEOL, Tokyo, Japan) with an acceleration voltage of $5.0 \mathrm{kV}$. The samples were crushed by the impact testing machine, gilded, and the surfaces were observed by SEM with a 1000x magnification (Hao et al. 2017).

\section{RESULTS AND DISCUSSION}

\section{Yield, Ash, and pH}

The yield, ash, and $\mathrm{pH}$ of the peanut straw biochar were in the ranges of $30.6 \%$ to $47.5 \%, 12.7 \%$ to $19.4 \%$, and 8.2 to 10.4 , respectively (Table 2). As the pyrolysis temperature was increased from $350{ }^{\circ} \mathrm{C}$ to $650{ }^{\circ} \mathrm{C}$, the biochar yield decreased from $47.5 \%$ to $30.6 \%$. This result was consistent with prior studies (Xu et al. 2013; Cha et al. 2016). The results were consistent with the large amounts of organic matter in peanut straw (cellulose, hemicellulose, lignin, fats, etc.).

The organic matter was easily decomposed and transformed at a high pyrolysis temperature (Kong and Zhou 2015). The ash contained many inorganic substances (heavy metals, phosphorus, sulfur, etc.) and minerals (phosphates, carbonates, etc.), which played key roles in the physicochemical characteristics of biochar and soil remediation (Zhou et al. 2016).

As the pyrolysis temperature increased from $350{ }^{\circ} \mathrm{C}$ to $650{ }^{\circ} \mathrm{C}$, the ash content of the biochar increased from $12.7 \%$ to $19.4 \%$. Such results are consistent with other work Correia et al. 2017). As the ash content increased, the $\mathrm{pH}$ of the fresh biochar increased from 8.2 to 10.4 , due to the increase in the surface alkaline functional groups (Bai et al. 2017). The $\mathrm{pH}$ of the fresh biochar varied greatly when the temperature from $350{ }^{\circ} \mathrm{C}$ to $500{ }^{\circ} \mathrm{C}$, but little with the temperature changing from $500{ }^{\circ} \mathrm{C}$ to $650{ }^{\circ} \mathrm{C}$. The ash content and pyrolysis temperature were the main factors that affected the biochar $\mathrm{pH}$ (Zhou et al. 2015).

The $\mathrm{pH}$ decreased with the aging of the peanut straw biochar, which was reported in many studies (Bakshi et al. 2016; Cao et al. 2017). After freeze-thaw aging, the $\mathrm{pH}$ of the biochar decreased from 8.2 to 8.2 at $350{ }^{\circ} \mathrm{C}$, from 9.8 to 9.2 at $500{ }^{\circ} \mathrm{C}$, and from 10.4 to 9.4 at $650{ }^{\circ} \mathrm{C}$. After dry-wet aging, the $\mathrm{pH}$ of the biochar decreased from 8.2 to 7.5 at $350{ }^{\circ} \mathrm{C}$, from 9.8 to 8.7 at $500{ }^{\circ} \mathrm{C}$, and from 10.4 to 9.1 at $650{ }^{\circ} \mathrm{C}$ (Table 1 ). In this study, aging affected the biochar $\mathrm{pH}$. With higher pyrolysis temperatures, the effect was clearer. Moreover, the effect of dry-wet aging on the biochar $\mathrm{pH}$ was greater than that of freezethaw aging. The decrease in the $\mathrm{pH}$ of the aged biochar was attributed to the oxidation of the biochar surface and enhancement of the biochar acidic groups (Mukherjee et al. 2014). As time passed, the abiotic chemical adsorption of oxygen and moisture on the surface of the biochar increased, which resulted in the decreased $\mathrm{pH}$ of the aged biochar. Other researchers explained that the decrease in the $\mathrm{pH}$ of aged biochar was because of the dissolution of some basic substances (carbonates, hydroxides, etc.) contained in the biochar (Xu et al. 2018). 
Table 2. Yield, Ash, and $\mathrm{pH}$ of the Biochar

\begin{tabular}{|c|c|c|c|c|c|c|}
\hline \multicolumn{2}{|c|}{ Biochar Sample } & \multirow{2}{*}{ Yield (\%) } & Ash (\%) & \multicolumn{3}{|c|}{$\mathrm{pH}^{*}$} \\
\cline { 1 - 3 } \cline { 5 - 7 } Straw & $\begin{array}{c}\text { Temperature } \\
\left({ }^{\circ} \mathrm{C}\right)\end{array}$ & & & Fresh & $\begin{array}{c}\text { Freeze-thaw } \\
\text { Aging }\end{array}$ & $\begin{array}{c}\text { Dry-wet } \\
\text { Aging }\end{array}$ \\
\hline \multirow{3}{*}{ Peanut } & 350 & $47.5 \pm 0.011$ & $12.7 \pm 0.002$ & $8.2 \pm 0.136$ & $8.2 \pm 0.050$ & $7.5 \pm 0.015$ \\
\cline { 2 - 3 } & 500 & $35.2 \pm 0.001$ & $17.7 \pm 0.005$ & $9.8 \pm 0.052$ & $9.2 \pm 0.041$ & $8.7 \pm 0.083$ \\
\cline { 2 - 3 } & 650 & $30.6 \pm 0.003$ & $19.4 \pm 0.003$ & $10.4 \pm 0.011$ & $9.4 \pm 0.061$ & $9.1 \pm 0.066$ \\
\hline
\end{tabular}

* Data is the mean \pm standard deviation based on duplicate measurements

\section{Elemental Analysis}

The elemental compositions of the fresh and aged biochar samples are shown in Table 3. There was a remarkable difference in the elemental contents of the biochar at the same temperatures. The elemental analysis of the biochar samples showed that as the pyrolysis temperature was increased, the $\mathrm{C}$ and $\mathrm{N}$ contents increased gradually, whereas the $\mathrm{H}$ and $\mathrm{O}$ contents decreased gradually. This indicated that the degree of biochar carbonization increased (Zhao et al. 2018). This phenomenon was mainly attributed to the influence of oxygen-containing functional groups (decarboxylation, dehydration, etc.) with the increase in the pyrolysis temperature and the loss of a large amount of $\mathrm{H}$ and $\mathrm{O}$ (Wang et al. 2013). The $(\mathrm{N}+\mathrm{O}) / \mathrm{C}, \mathrm{H} / \mathrm{C}$, and $\mathrm{O} / \mathrm{C}$ ratios are indicators of the biochar polarity $(\mathrm{Qu}$ et al. 2016), aromatics, and hydrophilicity, respectively (Ren et al. 2018). The polarity and hydrophilicity increased, and the aromatics decreased with an increase in the ratios. The $(\mathrm{N}+\mathrm{O}) / \mathrm{C}$, the $\mathrm{O} / \mathrm{C}$ and $\mathrm{H} / \mathrm{C}$ ratios decreased gradually with an increase in the pyrolysis temperature (Table 2) due to the thermal transformation of organic matter into carbonized organic matter and the formation of structures containing condensed carbons, such as aromatic rings (Qian and Chen 2014).

Table 3. Elemental Compositions of the Fresh Biochar and Aged Biochar Samples

\begin{tabular}{|c|c|c|c|c|c|c|c|c|}
\hline $\begin{array}{c}\text { Biochar } \\
\text { Sample }\end{array}$ & $\mathrm{C}(\%)$ & $\mathrm{N}(\%)$ & $\mathrm{H}(\%)$ & $\mathrm{O}(\%)$ & Ash (\%) & $(\mathrm{N}+\mathrm{O}) / \mathrm{C}$ & $\mathrm{H} / \mathrm{C}$ & $\mathrm{O} / \mathrm{C}$ \\
\hline P-350 & 58.77 & 1.74 & 4.36 & 22.46 & 12.67 & 0.41 & 0.07 & 0.38 \\
\hline P-500 & 60.12 & 1.85 & 2.98 & 17.39 & 17.66 & 0.32 & 0.05 & 0.29 \\
\hline P-650 & 61.42 & 1.94 & 2.13 & 15.13 & 19.38 & 0.28 & 0.03 & 0.25 \\
\hline \hline PF-350 & 51.60 & 1.53 & 4.79 & 28.26 & 13.82 & 0.58 & 0.09 & 0.55 \\
\hline PF-500 & 49.13 & 1.17 & 3.65 & 34.82 & 11.23 & 0.73 & 0.07 & 0.71 \\
\hline PF-650 & 57.90 & 0.51 & 2.38 & 26.56 & 12.65 & 0.47 & 0.04 & 0.46 \\
\hline \hline PD-350 & 46.91 & 1.36 & 4.33 & 26.48 & 20.92 & 0.59 & 0.09 & 0.56 \\
\hline PD-500 & 60.93 & 1.31 & 3.52 & 21.05 & 13.19 & 0.37 & 0.06 & 0.35 \\
\hline PD-650 & 55.28 & 0.69 & 2.07 & 14.82 & 27.14 & 0.28 & 0.04 & 0.27 \\
\hline
\end{tabular}

P - peanut straw biochar; PF — Freeze-thaw aging biochar; PD — dry-wet aging biochar 
After freeze-thaw and dry-wet aging, the elemental compositions of the biochar samples were noticeably changed. After aging, the proportional $\mathrm{C}$ contents markedly decreased and the $\mathrm{O}$ contents increased remarkably. Meanwhile, the $\mathrm{N}$ and $\mathrm{H}$ contents did not change greatly and the ash contents showed no clear pattern (Table 3 ). The oxygen contents of the aged biochar samples increased remarkably, which might have been because of the environmental changes (temperature, humidity, etc.) of the biochar samples and the oxidation of the biochar surface (Cao 2017). The polarity and hydrophilicity of the biochar samples were notably enhanced, whereas the aromaticity remained unchanged. The elemental compositions of the biochar samples pyrolyzed at the same temperature changed differently because of the different means of aging. A changing trend in the elemental content of aged biochar has been reported (Hao et al. 2017), and the experimental results followed this trend.

\section{BET and Pore Diameter Distribution}

Table 4 shows the comparison of the surface area and pore size between the fresh and aged biochar samples. There were more obvious differences between the fresh and aged biochar samples.

Table 4. Comparison of the Surface Area, Porosity, and Average Diameter between the Fresh and Aged Biochar Samples

\begin{tabular}{|c|c|c|c|}
\hline Biochar Sample & $\begin{array}{c}\text { Surface Area } \\
\left(\mathrm{m}^{2} / \mathrm{g}\right)\end{array}$ & $\begin{array}{c}\text { Mesoporous Volume } \\
\left(10^{-2} \mathrm{~cm}^{3} / \mathrm{g}\right)\end{array}$ & $\begin{array}{c}\text { Average Pore Diameter } \\
(\mathrm{nm})\end{array}$ \\
\hline P-350 & 1.431 & 0.36 & 25.169 \\
\hline P-500 & 1.636 & 0.43 & 14.655 \\
\hline P-650 & 121.326 & 4.52 & 10.856 \\
\hline PF-350 & 2.594 & 0.65 & 9.256 \\
\hline PF-500 & 11.640 & 8.50 & 17.749 \\
\hline PF-650 & 250.134 & 7.09 & 4.105 \\
\hline PD-350 & 2.133 & 4.04 & 73.879 \\
\hline PD-500 & 1.062 & 1.27 & 43.570 \\
\hline PD-650 & 217.823 & 7.45 & 5.061 \\
\hline
\end{tabular}

The surface area and mesoporous volume of the biochar generally increased as the pyrolysis temperature increased ( $\mathrm{Li}$ et al. 2017), due to the increase of cracking degrees, the gradual development of the pore structure, and the increase in the porosity (Lang et al. 2014). This indicated that the aging caused increases in the surface area and mesoporous volume due to the change of environment (temperature, humidity, etc.), gradual development of the pore structure, and influence of the temperature on the surface area and mesoporous volume of the biochar samples. Moreover, the effect of the temperature on the biochar samples was greater than that of the humidity. This phenomenon was similar to that of Miao (2014). However, some studies found that aging treatment could dissolve and reprecipitate inorganic substances in biochar, causing the pores of biochar to be blocked, or the microorganisms in the soil to cover the surface of biochar, reducing the specific surface area of biochar. This may be the aging time of this study was shorter than Hale et al. (2011) and Mukherjee et al. (2014). During this aging period, the development of pore structure on the surface of biochar was greater than that of pore plugging of biochar. 
The average pore diameters of the biochar and aged biochar samples (except PD350) ranged from $4.105 \mathrm{~nm}$ to $43.570 \mathrm{~nm}$, which indicated a mesoporous structure (Shen et al. 2015). The average pore diameter of the samples decreased with the increase of temperature, which may have been due in part to the collapse of some macropores and increase in the micropore proportion (An et al. 2011).

The pore diameter distributions of the fresh and aged biochar samples are shown in Fig. 1. The biochar samples had a narrow pore size distribution and the pore peaks of the biochar were mainly distributed between $2 \mathrm{~nm}$ and $10 \mathrm{~nm}$, with a number of mesoporous structures. The pore peaks of PD-350 were above $100 \mathrm{~nm}$, and the pore structure was macroporous, because of the effect of dry-wet aging on the pore structure. Overall, the surface area and pore size were greatly affected by the pyrolysis temperature, ambient temperature, and humidity, and their degrees of influence were different.

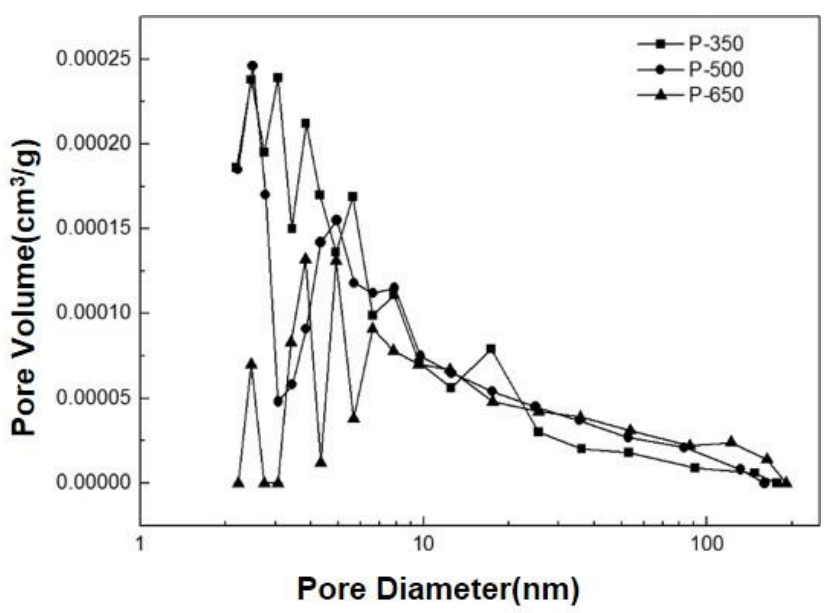

(a)

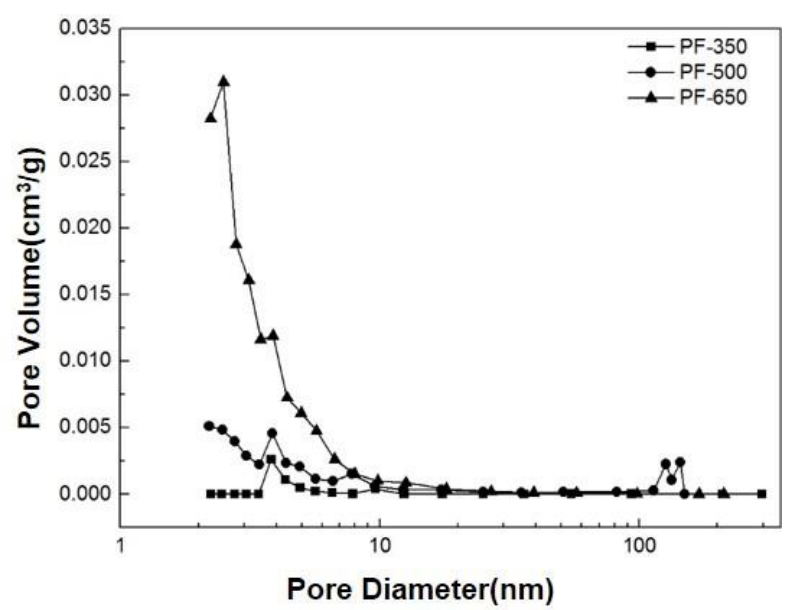

(b)

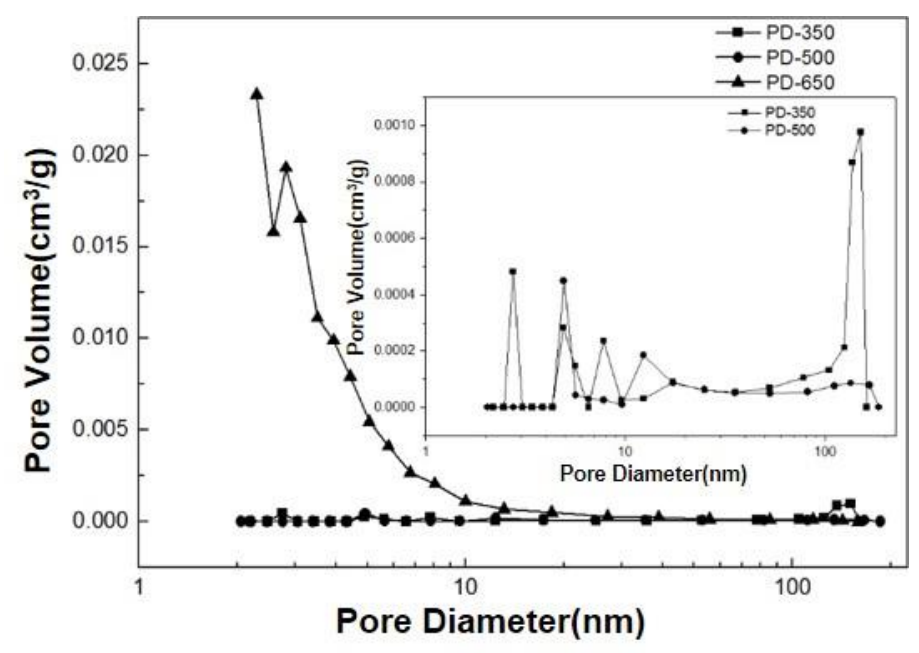

(c)

Fig. 1. Pore diameter distributions of the (a) pyrolysis, (b) pyrolysis and freeze-thaw aged, and (c) pyrolysis and dry-wet aged biochar samples 


\section{FTIR Analysis}

The FTIR spectra of the fresh and aged biochar samples are shown in Fig. 2. The peak at $3400 \mathrm{~cm}^{-1}$ was attributed to $\mathrm{O}-\mathrm{H}$ stretching of hydroxyl $(-\mathrm{OH})$ groups (Wang et al. 2013), which was weakened as the temperature increased. The peak at $1590 \mathrm{~cm}^{-1}$ was attributed to $\mathrm{C}=\mathrm{C}$ and $\mathrm{C}=\mathrm{O}$ stretching of aromatic rings (Liu et al. 2018), which was diminished or even disappeared as the pyrolysis temperature increased. The peaks centered at $1430 \mathrm{~cm}^{-1}$ were attributed to carboxylic $(-\mathrm{COOH})$ and aldehyde $(-\mathrm{CHO})$ groups, at 1100 $\mathrm{cm}^{-1}$ to C-O stretching of phenolic and -OH groups (Özçimen and Ersoy-Meriçboyu 2010), and at $860 \mathrm{~cm}^{-1}$ and $780 \mathrm{~cm}^{-1}$ to $\mathrm{C}-\mathrm{O}$ stretching of epoxide, which were diminished or even disappeared as the pyrolysis temperature increased. The acidic functional groups content in the peanut straw biochar decreased with the increase in the pyrolysis temperature (Keiluweit et al. 2010), which showed that the biochar alkalinity was enhanced with the increase in the pyrolysis temperature. The aromatic functional groups of the biochar increased gradually at higher temperatures, and their properties tended to be stable (Peng et al. 2011).

Compared with the FTIR spectra of the fresh biochar samples, a remarkable change in the surface functional groups of the aged biochar samples was observed (Fig. 2). In the FTIR spectra of the aged biochar samples, the peak at $3341 \mathrm{~cm}^{-1}$ was assigned to $-\mathrm{OH}$ stretching vibrations (Liu et al. 2018). The peaks at $2980 \mathrm{~cm}^{-1}, 2921 \mathrm{~cm}^{-1}$, and $2880 \mathrm{~cm}^{-1}$ were assigned to aliphatic C-H stretching (Peng et al. 2011), while the peaks at $1694 \mathrm{~cm}^{-1}$ and $1567 \mathrm{~cm}^{-1}$ were assigned to $\mathrm{C}=\mathrm{O}$ stretching of carboxylic acid (Keiluweit et al. 2010). The peaks at $1602 \mathrm{~cm}^{-1}$ and $1440 \mathrm{~cm}^{-1}$ were assigned to $\mathrm{C}=\mathrm{C}$ and $\mathrm{C}=\mathrm{O}$ stretching of aromatic rings, respectively (Wang et al. 2018). The peak at $1593 \mathrm{~cm}^{-1}$ was assigned to aromatic $\mathrm{C}=\mathrm{O}$ stretching, and those at $1226 \mathrm{~cm}^{-1}$ and $1205 \mathrm{~cm}^{-1}$ were assigned to aliphatic C-O stretching. The peaks at $1063 \mathrm{~cm}^{-1}, 1055 \mathrm{~cm}^{-1}, 1047 \mathrm{~cm}^{-1}$, and $596 \mathrm{~cm}^{-1}$ were assigned to Si-O stretching of organosilicon compounds (Li et al. 2015a). The peaks at $995 \mathrm{~cm}^{-1}$, $846 \mathrm{~cm}^{-1}$, and $752 \mathrm{~cm}^{-1}$ were assigned to $\mathrm{C}-\mathrm{H}$ bending vibrations of alkenes (Li et al. 2015b). Overall, with aging, the surface functional group content of the biochar samples increased but the surface - $\mathrm{OH}$ group content decreased. The surface acidic functional groups content (e.g., carboxylic acid) increased, which contributed to the decrease in the alkalinity of the aged biochar samples. This also demonstrated that aging could decrease the biochar alkalinity. Freeze-thaw aging had a greater effect on the surface functional groups of the peanut biochar than wet-dry aging, which indicated that both the temperature and humidity can affect the biochar surface functional groups. Furthermore, the influence of the temperature was greater than that of the humidity.

\section{Scanning Electron Microscopy}

The SEM images of the fresh and aged biochar samples showed the change in the surface morphology and pore structure of the biochar. Figure 3 presents SEM images of the peanut straw biochar before and after aging. There were notable differences in the surface morphologies of the pyrolytic biochar at different temperatures (P-350, P-500, and P-650). The surface smoothness of the biochar samples decreased as the temperature increased, and the number of micropores and clarity increased as the temperature increased. As the pyrolysis temperature increased, some phenomena were observed. The biochar surface became rough, the number of surface micropores increased, the pore structure became clearer, the pore size increased relatively, and the pore walls became thinner. 


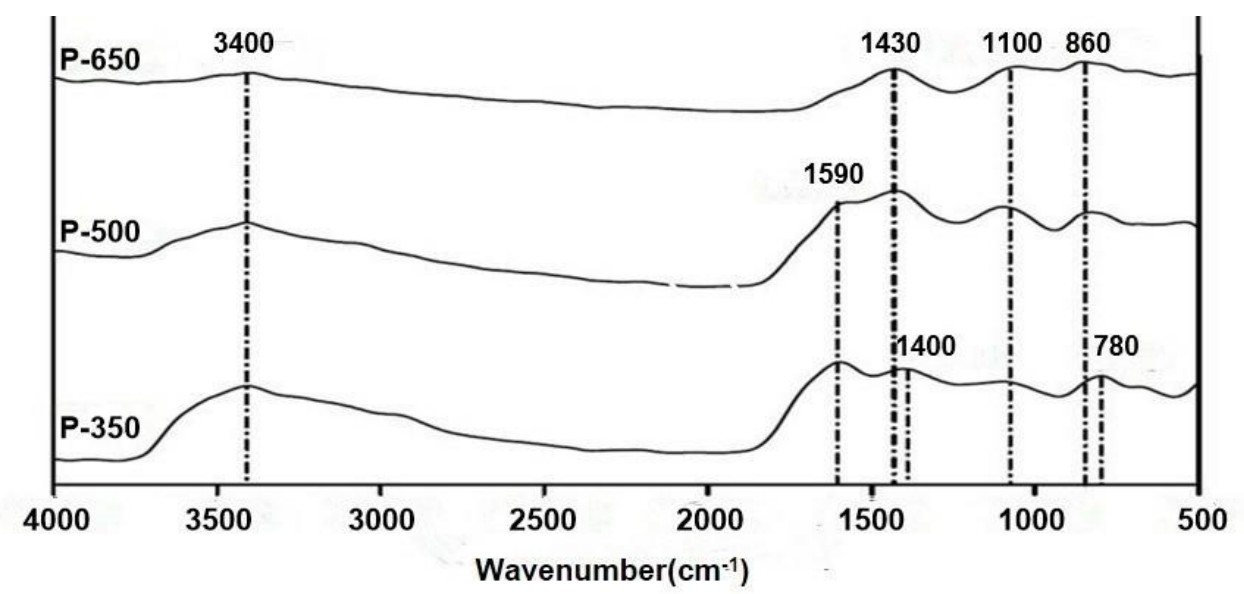

(a)

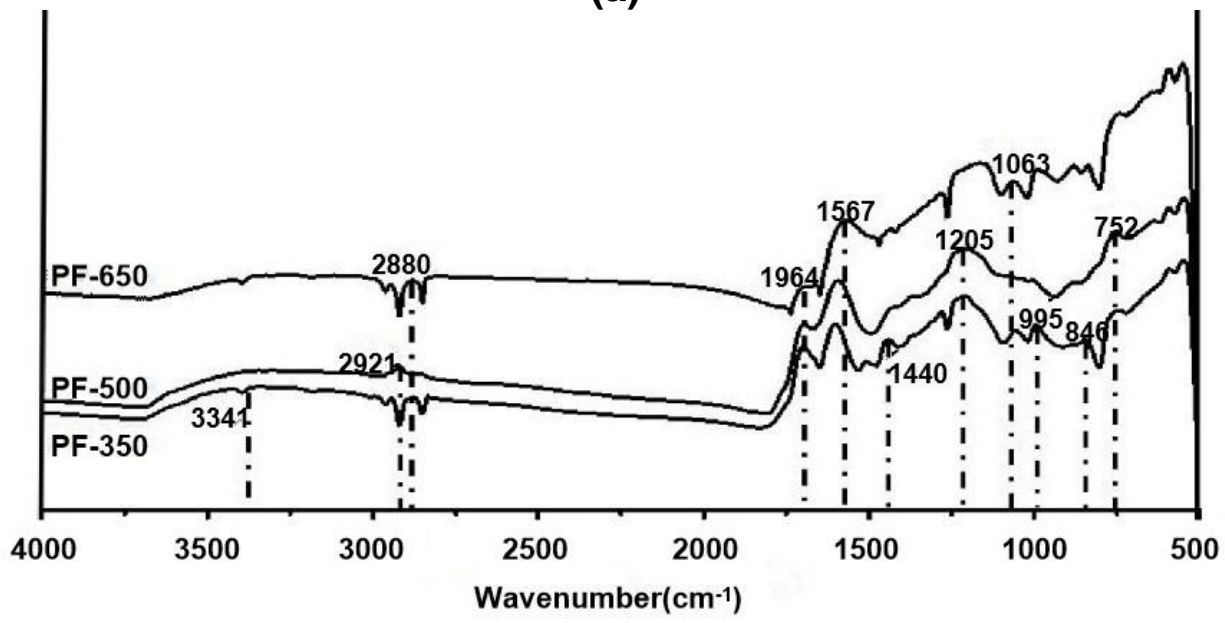

(b)

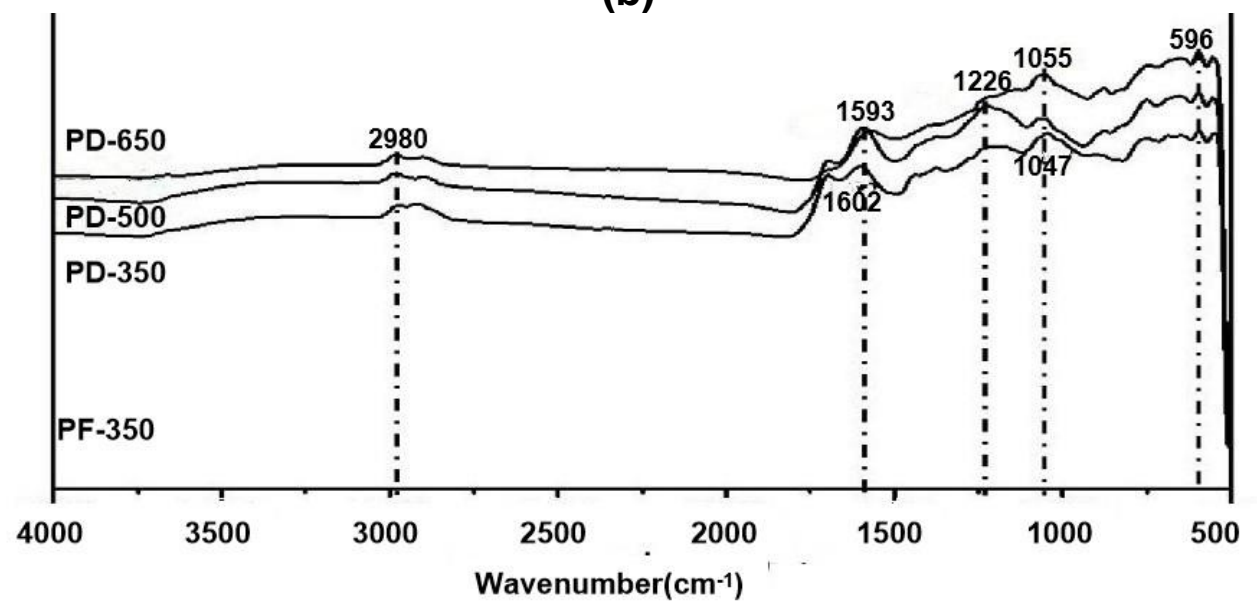

(c)

Fig. 2. FTIR spectra of the (a) pyrolysis, (b) pyrolysis and freeze-thaw aged, and (c) pyrolysis and dry-wet aged biochar samples

Differences in the cellulose, hemicellulose, and lignin residue contents were the main reasons for the changes in the surface morphology and pore structure of the biochar with the temperature (Cheng 2014). The cellulose content in the peanut straw was relatively 
high, and it was burned and dehydrated gradually with the increase in the pyrolysis temperature, while the lignin content was relatively low, which made the biochar change from a crumbly structure to a tubular structure.

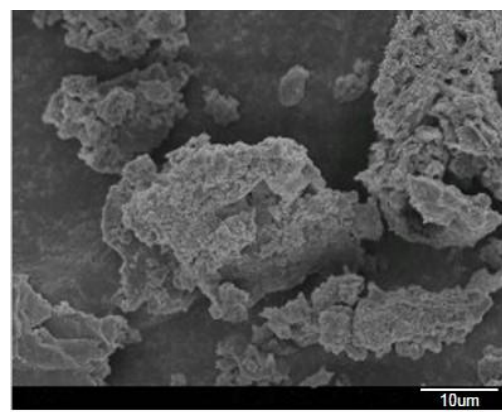

(a)

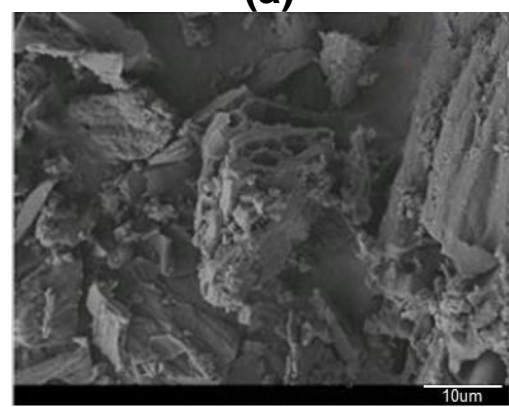

(d)

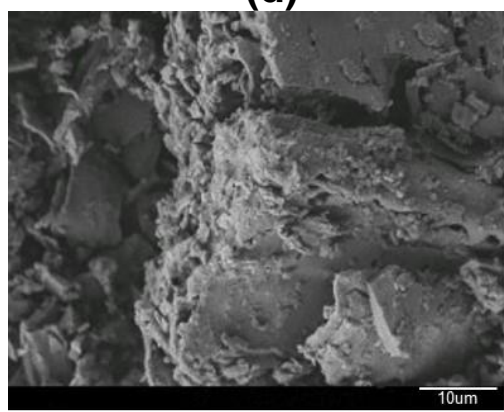

(g)

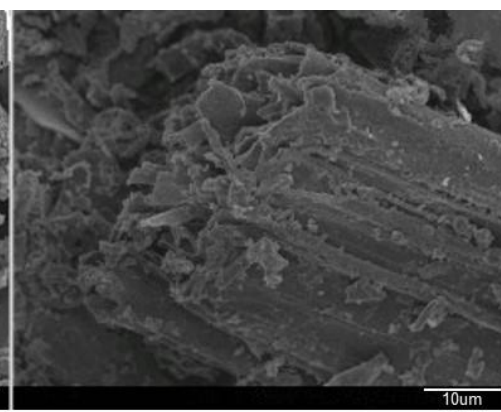

(b)

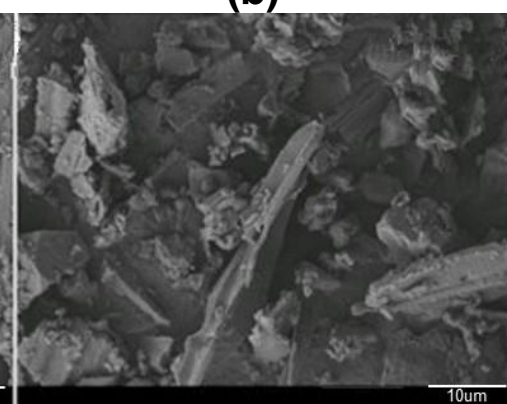

(e)

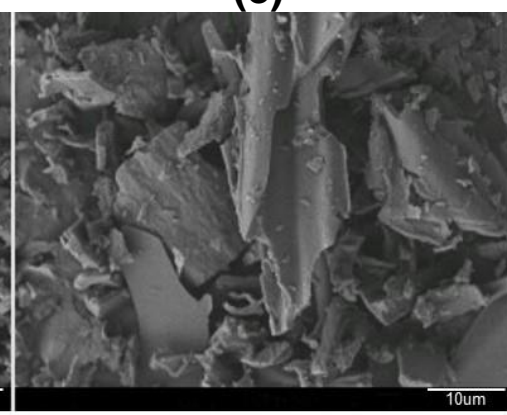

(h)

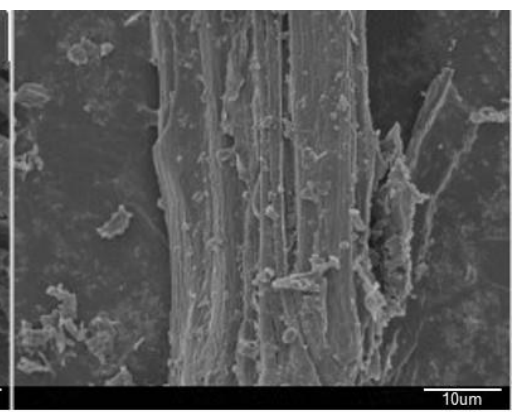

(c)

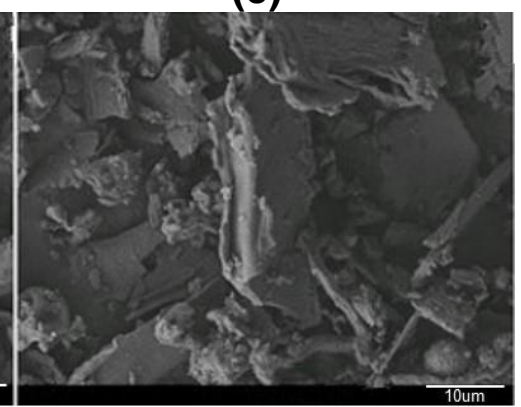

(f)

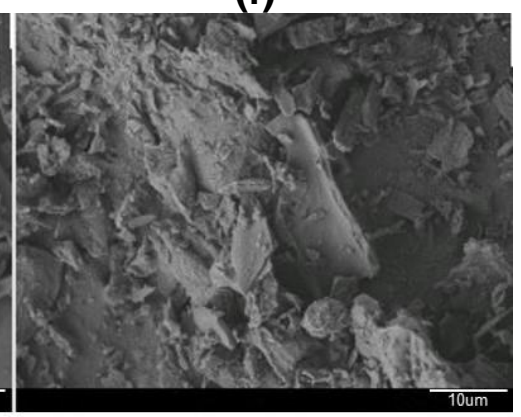

(i)

Fig. 3. SEM images of the fresh and aged biochar samples: (a) P-350; (b) P-500; (c) P-650; (d) PF-350; (e) PF-500; (f) PF-650; (g) PD-350; (h) PD-500; and (i) PD-650

After freeze-thaw and dry-wet aging, the surface morphology and pore structure of the peanut straw biochar changed greatly. The main manifestation was that the unbroken crumbly structure of the biochar prepared at $350{ }^{\circ} \mathrm{C}$ was destroyed and became a fragmented tubular structure. The integrated crumbly structure of the biochar pyrolyzed at $500{ }^{\circ} \mathrm{C}$ and $650{ }^{\circ} \mathrm{C}$ was also broken into sheet structures. The surface smoothness of the biochar pyrolyzed at the same temperature decreased after it was aged, with the following order: P-650 > PF-650 > PD-650. The number of biochar surface micropores and porosity changed, with no concrete regularity. The effect of dry-wet aging on the surface morphology and pore structure of the biochar was greater than that of freeze-thaw aging. The surface smoothness of the biochar decreased and the surface morphology of the biochar was broken, and the unbroken shapes became fragmented. 


\section{CONCLUSIONS}

1. The pyrolysis temperature was found to be one of the main factors that affected the physicochemical characteristics of the biochar. The biochar yield decreased with an increasing pyrolysis temperature, while the ash content and $\mathrm{pH}$ increased. The elemental content of the biochar varied with the pyrolysis temperature. The pyrolysis temperature affected the polarity, aromaticity, and hydrophilicity of the biochar. With an increase in the pyrolysis temperature, the specific surface area, mesoporous volume, and number of surface micropores of the biochar also increased, while the average pore diameter, surface smoothness, and surface acidic functional groups of the biochar decreased.

2. The temperature and moisture content were the main factors that affected aging of the biochar and had a remarkable impact on its physicochemical characteristics. After aging, the $\mathrm{pH}$ and $\mathrm{C}$ content of the biochar decreased, while the $\mathrm{O}$ content increased, which further changed the polarity, aromaticity, and hydrophilicity of the aged biochar. Furthermore, the effect of dry-wet aging was greater than that of freeze-thaw aging. The effect of freeze-thaw aging on the specific surface area and micropore volume of the aged biochar was greater than that of dry-wet aging, and the pore structure of the aged biochar was mainly mesoporous. Aging resulted in an increase in the surface acidic functional groups and a decrease in the aromatic functional groups, which corresponded with the alkalinity decrease and collapse of the stability of the aged biochar.

3. The unbroken structure of the biochar surface was broken into a fragmented structure with aging.

4. The physicochemical characteristics of the biochar were influenced by many factors. The different physicochemical properties of the biochar varied with the temperature and humidity. Therefore, the effects of dry-wet and freeze-thaw aging on biochar should be analyzed under different conditions.

\section{ACKNOWLEDGMENTS}

This research was supported by the Natural Science Foundation of Shandong Province (No. ZR2013DM005). The authors extend sincere gratitude to Wenliang Ju for help setting up and running the experiments.

\section{REFERENCES CITED}

An, Z., Hou, Y., Cai, C., and Xue, X. (2011). "Lead(II) adsorption characteristics on different biochars derived from rice straw," Environ. Chem. 30(11), 1851-1857.

Bai, X., Zhou, X., Li, Z., Ni, J., and Bai, X. (2017). "Properties and applications of biochars derived from different biomass feedstock sources," Int. J. Agr. Biol. Eng. 10(2), 242-250. DOI: 10.3965/j.ijabe.20171002.2878 
Bakshi, S., Aller, D. M., Laird, D. A., and Chintala, R. (2016). "Comparison of the physical and chemical properties of laboratory and field-aged biochars," J. Environ. Qual. 45(5), 1627-1634. DOI: 10.2134/jeq2016.02.0062

Cao, T., Chen, W., Yang, T., He, T., Liu, Z., and Meng, J. (2017). "Surface characterization of aged biochar incubated in different types of soil," BioResources 12(3), 6366-6377. DOI: 10.15376/biores.12.3.6366-6377

Cha, J. S., Park, S. H., Jung, S.-C., Ryu, C., Jeon, J.-K., Shin, M.-C., and Park, Y.-K. (2016). "Production and utilization of biochar: A review," J. Ind. Eng. Chem. 40, 115. DOI: $10.1016 /$ j.jiec.2016.06.002

Chen, W., Zhang, W., Meng, J., and Xu, Z. (2011). "Researches on biochar application technology," Engineering Sciences 13(2), 83-89.

Cheng, J. (2014). Chemical and Thermal Stability Comparison of Biochars Produced from Two Types of Biomasses, Master's Thesis, Kunming University of Science and Technology, Kunming, China.

Correia, R., Gonçalves, M., Nobre, C., and Mendes, B. (2017). "Impact of torrefaction and low-temperature carbonization on the properties of biomass wastes from Arundo donax L. and Phoenix canariensis," Bioresource Technol. 223, 210-218. DOI: 10.1016/j.biortech.2016.10.046

Dong, Q., Li, H., Niu, M., Luo, C., Zhang, J., Qi, B., Li, X., and Zhong, W. (2018). "Microwave pyrolysis of moso bamboo for syngas production and bio-oil upgrading over bamboo-based biochar catalyst," Bioresource Technol. 266, 284-290. DOI: 10.1016/j.biortech.2018.06.104

Fan, Q., Sun, J., Chu, L., Cui, L., Quan, G., Yan, J., Hussain, Q., and Iqbal, M. (2018). "Effects of chemical oxidation on surface oxygen-containing functional groups and adsorption behavior of biochar," Chemosphere 207, 33-40. DOI: 10.1016/j.chemosphere.2018.05.044

GB/T 12496.3 (1999). "Test methods of wooden activated carbon - Determination of ash content," Standardization Administration of China, Beijing, China.

GB/T 12496.7 (1999). "Test methods of wooden activated carbon - Determination of $\mathrm{pH}$," Standardization Administration of China, Beijing, China.

GB/T 17664 (1999). "Wood charcoal and test methods of wood charcoal," Standardization Administration of China, Beijing, China.

Glaser, B., Lehmann, J., and Zech, W. (2002). "Ameliorating physical and chemical properties of highly weathered soils in the tropics with charcoal - A review," Biol. Fert. Soils 35(4), 219-230. DOI: 10.1007/s00374-002-0466-4

Guo, Y., Tang, W., Wu, J.-g., Huang, Z.-q., and Dai, J.-y. (2014). "Mechanism of Cu (II) adsorption inhibition on biochar by its aging process," Journal of Environmental Sciences 26(10), 2123-2130. DOI: 10.1016/j.jes.2014.08.012

Hale, S. E., Hanley, K., Lehmann, J., Zimmerman, A. R., and Cornelissen, G. (2011). "Effects of chemical, biological, and physical aging as well as soil addition on the sorption of pyrene to activated carbon and biochar," Environ. Sci. Technol. 45(24), 10445-10453. DOI: 10.1021/es202970x

Hao, H., Jing, Y.-d., Ju, W.-1., Shen, L., and Cao, Y.-q. (2017). "Different types of biochar: Effect of aging on the $\mathrm{Cu}(\mathrm{II})$ adsorption behavior," Desalin. Water Treat. 95, 227-233. DOI: 10.5004/dwt.2017.21524

Heitkötter, J., and Marschner, B. (2015). "Interactive effects of biochar ageing in soils related to feedstock, pyrolysis temperature, and historic charcoal production," Geoderma 245-246, 56-64. DOI: 10.1016/j.geoderma.2015.01.012 
Iftikhar, S., Ahmad, K. S., and Gul, M. M. (2018). "Low-cost and environmental-friendly Triticum aestivum-derived biochar for improving plant growth and soil fertility," Commun. Soil Sci. Plan. 49(22), 2814-2827. DOI: 10.1080/00103624.2018.1546869

Joseph, S. D., Camps-Arbestain, M., Lin, Y., Munroe, P., Chia, C. H., Hook, J., van Zwieten, L., Kimber, S., Cowie, A., Singh, B. P., et al. (2010). "An investigation into the reactions of biochar in soil," Aust. J. Soil Res. 48(7), 501-515. DOI: 10.1071/SR10009

Ju, W.-1., Jing, Y.-d. (2017). "Effect of aging treatment on physicochemical characteristics of cotton straw biochar," Acta Scientiae Circumstantiae 37(10), 38533861. DOI: 10.13671/j.hjkxxb.2017.0188

Keiluweit, M., Nico, P. S., Johnson, M. G., and Kleber, M. (2010). "Dynamic molecular structure of plant biomass-derived black carbon (biochar)," Environ. Sci. Technol. 44(4), 1247-1253. DOI: 10.1021/es9031419

Kong, L., and Zhou, Q. (2015). "Characterization of new-prepared biochars and their adsorption effectiveness on petroleum hydrocarbon contaminated soil," Chinese Journal of Environmental Engineering 9(5), 2462-2468.

Lang, Y.-H., Liu, W., and Wang, H. (2014). "Adsorption efficiencies of pentachlorophenol from aqueous solution onto biochars," China Environmental Science 34(8), 2017-2023.

Leng, L., and Huang, H. (2018). "An overview of the effect of pyrolysis process parameters on biochar stability," Bioresource Technol. 270, 627-642. DOI: 10.1016/j.biortech.2018.09.030

Li, H., Dong, X., da Silva, E. B., de Oliveira, L. M., Chen, Y., and Ma, L. Q. (2017). "Mechanisms of metal sorption by biochars: Biochar characteristics and modifications," Chemosphere 178, 466-478. DOI: 10.1016/j.chemosphere.2017.03.072

Li, R.-y., Chen, D., Li, L.-q., Pan, G.-x., Chen, J.-q., and Guo, H. (2015a). "Adsorption of $\mathrm{Pb}^{2+}$ and $\mathrm{Cd}^{2+}$ in aqueous solution by biochars derived from different crop residues," Journal of Agro-Environment Science 34(5), 1001-1008.

Li, Y., Song, Y., Wang, F., Bian, Y., and Jiang, X. (2015b). "Effect of wheat straw biochar on high chlorinated benzene sorption process and mechanism," Acta Pedologica Sinica 52(5), 1096-1105. DOI: 10.11766/trxb201411050559

Liu, Z., Niu, W., Chu, H., Zhou, T., and Niu, Z. (2018). "Effect of the carbonization temperature on the properties of biochar produced from the pyrolysis of crop residues," BioResources 13(2), 3429-3446. DOI: 10.15376/biores.13.2.3429-3446

Miao, W. (2014). Aging Effect of Biochar on Soil Nutrients and Growth of Rice, Ph.D. Dissertation, Shenyang Agricultural University, Shenyang, China.

Mukherjee, A., Zimmerman, A. R., Hamdan, R., and Cooper, W. T. (2014). "Physicochemical changes in pyrogenic organic matter (biochar) after 15 months of field aging," Solid Earth 5(2), 693-704. DOI: 10.5194/se-5-693-2014

O’Connor, D., Peng, T., Zhang, J., Tsang, D. C. W., Alessi, D. S., Shen, Z., Bolan, N. S., and Hou, D. (2018). "Biochar application for the remediation of heavy metal polluted land: A review of in situ field trials," Sci. Total Environ. 619-620, 815-826. DOI: 10.1016/j.scitotenv.2017.11.132

Özçimen, D., and Ersoy-Meriçboyu, A. (2010). "Characterization of biochar and bio-oil samples obtained from carbonization of various biomass materials," Renew. Energ. 35(6), 1319-1324. DOI: 10.1016/j.renene.2009.11.042 
Peng, X., Ye, L. L., Wang, C. H., Zhou, H., and Sun, B. (2011). "Temperature- and duration-dependent rice straw-derived biochar: Characteristics and its effects on soil properties of an ultisol in southern China," Soil Till. Res. 112(2), 159-166. DOI: 10.1016/j.still.2011.01.002

Qian, L., and Chen, B. (2014). "Interactions of aluminum with biochars and oxidized biochars: Implications for the biochar aging process," J. Agr. Food Chem. 62(2), 373380. DOI: 10.1021/jf404624h

Qu, X., Fu, H., Mao, J., Ran, Y., Zhang, D., and Zhu, D. (2016). "Chemical and structural properties of dissolved black carbon released from biochars," Carbon 96, 759-767. DOI: 10.1016/j.carbon.2015.09.106

Ren, X., Wang, F., Zhang, P., Guo, J., and Sun, H. (2018). "Aging effect of minerals on biochar properties and sorption capacities for atrazine and phenanthrene," Chemosphere 206, 51-58. DOI: 10.1016/j.chemosphere.2018.04.125

Shen, W., Zhang, Y., Wang, Z., Xu, B., Han, F., and Zheng, J. (2015). "Pore structure analysis of biochars prepared by wood," China Powder Science and Technology 21(2), 24-27, 31. DOI: 10.13732/j.issn.1008-5548.2015.02.006

Surhone, L. M., Tennoe, M. T., Henssonow, S. F. (2002). "World reference base for soil resources", Soils of Tropical Forest Ecosystems Characteristics Ecology \& Management 41(9), 21-28. DOI: 10.1007/978-3-662-03649-5_2

Wang, P., Zhang, J., Shao, Q., and Wang, G. (2018). "Physicochemical properties evolution of chars from palm kernel shell pyrolysis," J. Therm. Anal. Calorim. 133(3), 1271-1280. DOI: 10.1007/s10973-018-7185-Z

Wang, Q., Li, F., Cao, X., and Zhao, L. (2013). "Difference between characteristics of biochars derived from plant and solid waste," Environ. Sci. Technol. 36(8), 1-5.

Wang, R.-f., Zhao, L.-x., Shen, Y.-j., Meng, H.-b., and Yang, H.-z. (2015). "Research progress on preparing biochar and its effect on soil physio-chemical properties," $J$. Agric. Sci. Technol. 17(2), 126-133. DOI: 10.13304/j.nykjdb.2014.624

Xu, Y.-p., Xie, Z.-b., Zhu, J.-g., Liu, G., and Liu, Q. (2013). "Effects of pyrolysis temperature on physical and chemical properties of corn biochar and wheat biochar," Soils 45(1), 73-78. DOI: 10.13758/j.cnki.tr.2013.01.027

Xu, Z., Xu, X., Tsang, D. C. W., and Cao, X. (2018). "Contrasting impacts of pre- and post-application aging of biochar on the immobilization of $\mathrm{Cd}$ in contaminated soils," Environ. Pollut. 242(Part B), 1362-1370. DOI: 10.1016/j.envpol.2018.08.012

Zhang, M.-k., Gu, G.-p., and Wang, Y. (2012). "Degradation characteristic of different biochar materials in soil environments," Journal of Zhejiang University (Agriculture and Life Sciences) 38(3), 329-335. DOI: 10.3785/j.issn.1008-9209.2012.03.014

Zhang, M., Jia, M.-y., Bian, Y.-r., Sheng, H.-j., Liu, G.-X., Wang, Y,-j., and Wang, F. (2015a). "Sorption kinetics and mechanism of naphthalene corn-stalk-derived biochar with different pyrolysis temperature," Acta Pedologica Sinica 52(5), 1106-1115. DOI: $10.11766 / \operatorname{trxb} 201412040623$

Zhang, X., He, L., Mao, X., and Wang, H. (2015b). "Effect of different aging processes on adsorption and desorption of diethyl phthalate to soil amended with biochars," Acta Scientiae Circumstantiae 35(12), 4012-4020. DOI: 10.13671/j.hjkxxb.2015.0499

Zhao, B., Xu, H., Zhang, T., Nan, X., and Ma, F. (2018). "Effect of pyrolysis temperature on sulfur content, extractable fraction and release of sulfate in corn straw biochar," $R S C A d v$. 8(62), 35611-35617. DOI: 10.1039/C8RA06382F 
Zhou, D., Ghosh, S., Zhang, D., Liang, N., Dong, X., Wu, M., and Pan, B. (2016). "Role of ash content in biochar for copper immobilization," Environ. Eng. Sci. 33(12), 962969. DOI: $10.1089 /$ ees.2016.0042

Zhou, Q., Huang, D.-k., Yu, L., and Peng, F.-r. (2015). "Effects of pyrolysis temperature, time and biochar mass ratio on $\mathrm{pH}$ value determination for four biochar solutions," Journal of Earth Environment 6(3), 195-200. DOI: 10.7515/JEE201503008

Article submitted: January 14, 2019; Peer review completed: March 18, 2019; Revised version received: April 2, 2019; Accepted: April 3, 2019; Published: April 16, 2019. DOI: $10.15376 /$ biores.14.2.4329-4343 